\title{
JUSTICIA CONSTITUCIONAL, LIBRE ELECCIÓN EN MATERIA DE SALUD Y NORMATIVA SOBRE ISAPRES: UN COMENTARIO A LA RECIENTE JURISPRUDENCIA DEL TRIBUNAL CONSTITUCIONAL
}

\author{
CONSTITUTIONAL JUSTICE: FREE CHOICE ON HEALTH PLANS \\ ISSUES AND ISAPRES REGULATION. AN ANALYSIS OF RECENT \\ JURISPRUDENCE OF THE CONSTITUTIONAL COURT
}

\author{
ÁNGELA ViVANCo MARTÍNEZ 1
}

\begin{abstract}
RESUMEN: El sistema de salud privado (ISAPRES) está construido sobre seguros autofinanciados, los que a su vez se fijan en función del riesgo de los beneficiarios y de la cobertura del plan respectivo. Tal modelo ha motivado la presentación de acciones de inaplicabilidad ante el Tribunal Constitucional contra el artículo 38 ter de la Ley No 18.933 -introducido por la Ley No 20.015-, que actualmente corresponde al artículo 199 del D.F.L. No 1, de 2005, de Salud, destinadas a evitar el incremento de los costos de los planes en razón de edad, argumentando que restringiría la voluntad del asegurado de decidir respecto del sistema de salud por el que se atenderá; que se obligaría a pagar una cantidad de dinero mayor a la que el interesado pagaba en plena actividad laboral y que se afectaría el patrimonio por un aumento de pagos "desmedido e irracional". El Tribunal ha resuelto estos requerimientos estimando la libertad de elección del sistema de salud como equivalente al derecho de permanecer en el mismo plan de salud contratado con la ISAPRE sin pagar el aumento de precio que resulta de la aplicación de la tabla de factores relativos incorporada al contrato, lo cual inciden gravemente en la esfera de los contratos e impone un principio de solidaridad a un modelo de otra naturaleza.
\end{abstract}

Palabras clave: ISAPRES, inaplicabilidad por inconstitucionalidad, Tribunal Constitucional, plan de salud, tabla de factores, derechos económicos y sociales, garantías prestacionales, libre elección en materia de salud.

ABSTRACT: The private health system (ISAPRES) is based on auto financed insurances which are established considering the risk of beneficiaries and the coverage of the respective plan. This model caused inapplicability actions to be seen by the Constitutional Court based in article 38 ter of Law No 18.933 -introduced by Law No 20.015- which currently corresponds to article 199 of D.F.L. No 1 of 2005 (Ministry of Health), that pretends to avoid cost that increases in health plans caused by age factors, arguing that it would restrict the will of the beneficiary in order to decide about the health system he or she will choose, something that would be more expensive comparing the prices paid during his or her work life, affecting its wealth as a consequence of "irrational and excessive payments". The Court has decided these actions stating that the free choice of a health system contains the right to remain in the same health plan

${ }^{1}$ Abogada UC, Candidata a Doctora en Derecho por la Universidad de La Coruña, España. Profesora de Derecho Constitucional y de Bioética y Persona en la Pontificia Universidad Católica de Chile, miembro del Centro de Estudios para el Derecho y la Ética Aplicada-CEDAP UC. Correo electrónico: avivancm@uc.cl. 
without paying the increase of the costs caused by the implementation of a relative table of factors incorporated to the contract, which would seriously affect the contracts and impose a solidarity principle to a model of a different nature.

Key words: ISAPRES, inapplicability due to unconstitutionality, Constitutional Court, health plan, table of factors, economic and social rights, assistance warranties, free choice on health issues.

\section{INTRODUCCIÓN}

\section{DERECHOS ECONÓMICOS Y SOCIALES. LAS GARANTÍAS PRESTACIONALES}

Los derechos económicos y sociales (DES) corresponden a la llamada segunda generación de derechos y su existencia histórica se ha asociado con la necesidad de establecer un "complemento a las insuficiencias constatadas en relación con los clásicos derechos de libertad para encargarse de algunos problemas y demandas sociales" ${ }^{2}$, corrigiendo así las inequidades de los sistemas sociales y estatales y la dificultad de consagración material del principio de igualdad.

La realidad de estos derechos crecientemente ha demandado que, agregadas a las garantías de orden negativo que limitan la acción del Estado y de las personas frente a realidades autogeneradas y desarrolladas por las personas, se establezcan garantías de intervención positiva, también llamadas garantías prestacionales, respecto de las cuales Alexy ha considerado la existencia de una amplia gama, que "se extiende desde la protección del ciudadano frente a los demás, a través de normas del derecho penal, pasando por la edición de normas de organización y procedimiento, hasta prestaciones en dinero y bienes"3.

Sin embargo, la idea prestacional /material que se ubica tras la existencia de estas garantías no representa solo una opción del modelo por privilegiar la entrega de recursos a quienes lo solicitan, sino la introducción de un criterio de solidaridad que se agrega al principio de dignidad que les dio origen: "Así, entendemos que aunque la dignidad sea innegablemente el núcleo de los derechos sociales, hay que observar que en el caso de los derechos sociales prestacionales esa exige, también, un importante complemento: la solidaridad. Como se ha visto, derechos prestacionales tienen por fundamento transferencias económicas o mantenimiento de estructuras a aquellos que no disponen de condiciones para obtener, por sí, algo que está disponible en el mercado. Por la dependencia de esa solidaridad, muchas veces la realización de los derechos sociales está condicionada a lo cuánto los demás están dispuestos a acceder o contribuir a la satisfacción de los derechos de esos más necesitados. Debido a eso, los derechos sociales, principalmente los prestacionales, están condicionados por decisiones políticas que expresarían ese acuerdo de solidaridad, es decir, esa autorización para la realización de la solidaridad por parte del Estado" ${ }^{4}$.

\footnotetext{
2 MOller (2008), p. 340.

${ }^{3}$ AleXY (2001), p. 427.

${ }^{4}$ MOLLER (2008) p. 357.
} 
El punto, sin duda, radica en la determinación de la contraparte de los titulares del derecho en esta materia y cuáles son sus condiciones de contribución a tal tarea social, pregunta que originalmente se respondió mediante la idea de un Estado social de Derecho entendido como "la forma de gobierno mediante la cual el Estado, haciendo uso de la legislación, asume la responsabilidad de proteger y promover el bienestar básico de todos sus miembros" $"$. Sin embargo, la crisis financiera de tales modelos y la internacionalización de las exigencias y estándares en torno a estos derechos ha motivado un descenso de la actividad del Estado en estas materias y un incremento de la carga de los particulares ante "expectativas o pretensiones de recursos y bienes dirigidos a satisfacer necesidades básicas de las personas... pero fundamentalmente a los miembros más vulnerables de la sociedad, cuyo acceso a dichos recursos suele ser escaso y a veces nulo o inexistente"6.

\section{LA CREACIÓN JURISPRUDENCIAL}

En esa perspectiva, algunos modelos jurisprudenciales han ido crecientemente afirmando la idea que las garantías prestacionales, más que un derecho constitucionalmente garantizado, pueden transformarse en un producto emanado de la interpretación que se hace por los tribunales y que las dota de contenido, proyectándolas hacia los sistemas privados de salud, previsión y educación, ya no solo en la perspectiva limitatoria y regulatoria, sino directamente de imposición de prestaciones solidarias aun más allá de contratos, estatutos jurídicos adquiridos o derechos de los restantes beneficiarios del sistema: "hay hoy un sentimiento difuso - pero no ideas claras- de que la dinamización de los derechos sociales pasa por una "des-introversión” del esquema jurídico de las relaciones de prestación. Quien paga no es el Estado: son unos ciudadanos que contribuyen ("los contribuyentes", los "tomadores de encargos", los "pagadores de prestaciones") y son otros los ciudadanos que reciben (los "beneficiarios", los "tomadores de prestaciones"). Esto es sabido y no pasa de una verificación banal..."7. Tal producción jurisprudencial, sin duda, representa para los tribunales una capacidad de revisión del ordenamiento jurídico en su conjunto sobre la base de una extensión considerable del principio de igualdad, pues ya no solo se trata del establecimiento de un estatuto igualitario, sino en la objeción de las diferencias justificadas en aras de establecer un sistema prestacional que puede o no ser sostenible en el tiempo sobre la base del principio "la igualdad no tiene necesidad, como tal, de justificación. El deber de justificación pesa, en cambio, sobre las desviaciones de la igualdad"8.

\footnotetext{
5 STEIN (1991), p. 207.

${ }^{6}$ Aguilera y Espino (2007) p. 123.

7 GÓMEZ CANOTILHO (1995) p. 39

8 PRIETO SANCHIS (1995), p. 26, citando a su vez a LAPORTA. Precisamente tal deber de justificación hace imposible sostener el principio asociado con la ejecución de las acciones prestacionales por entidades no estatales, ya que se les exige demostrar a estas cumplir con un deber de solidaridad al que está obligado el Estado.
} 


\section{EL DERECHO A LA PROTECCIÓN DE LA SALUD Y LA LIBRE ELECCIÓN DEL SISTEMA DE SALUD EN LA CARTA DE 1980}

\section{El ARTículo 19 No 9o de la CARTA Fundamental}

En el artículo 19 No $9^{\circ}$ de la Constitución Política de 1980 se asegura a todas las personas el derecho a la protección de la salud, como un derecho de carácter social que "está circunscrito en la posibilidad de ser satisfecho en plenitud por la capacidad económica del Estado, siempre limitada; pone en juego la obligación del Estado de actuar en forma dinámica y prioritaria entre sus preocupaciones dentro de este campo, y al mismo tiempo exige una armonización entre ese deber del Estado, que es prioritario entre sus deberes, y el derecho a los ciudadanos de participar como particulares en la actividad determinada, derecho que es preferente, incluso desde el punto de vista de la libertad, a la acción del Estado, acción que en este sentido, adquiere un carácter subsidiario" $"$.

No cabe duda que el interés originario del Constituyente de 1980, en el sentido de evitar los monopolios estatales respecto de distintas actividades y de asegurar la intervención privada en el mayor ámbito de materias, si bien permitió el establecimiento legal y material de dos fórmulas en materia de salud, la estatal a través de FONASA y la privada a través del sistema de ISAPRES, dejó algunos cabos sueltos, pues dio apertura a la actividad misma de la prestación en salud pero no se ocupó suficientemente de las diferencias sustanciales que residen en un sistema y en el otro, lo que ha significado que se igualen expectativas públicas respecto de situaciones del todo diversos y que se pretenda hacer valer por los usuarios del sistema una identificación aventurada, consistente en estimar que la libre elección de sistema de salud garantizada asimismo en este numeral debe importar que ambos sistemas resulten de acceso fácil a todo público y se mantengan inmutables, evitando generar situaciones de diferenciación que podrían forzar el cambio de sistema por el interesado, desconociendo que "al implementar acciones para satisfacer determinadas exigencias no hay modelo que pueda sustraerse de hacer, de alguna manera, discriminaciones que suscitan reparos sobre la justicia o transparencia de tales opciones. La causa no es otra que la lógica limitación de recursos ante demandas sanitarias que exceden las disponibilidades" ${ }^{10}$.

\section{EL RECURSO DE PROTECCIÓN EN MATERIA DE LIBRE ELECCIÓN DEL SISTEMA DE SALUD}

Si bien la libre elección tiene una vinculación clara con los recursos individuales y estatales disponibles y no se puede garantizar entonces de modo absoluto, en la medida que el artículo 20 de la Carta admite la presentación de un recurso de protección al existir un comportamiento ilegal o arbitrario que prive, perturbe o amenace el legítimo ejercicio del derecho a la libre elección de sistema de salud por parte del titular, ha motivado la generación de diversas instancias judiciales precisamente en torno a esa

\footnotetext{
${ }^{9}$ Actas Oficiales de la Comisión de Estudios de la Nueva Constitución, sesión no 187, p. 7.

${ }^{10}$ Rosselot (2003).
} 
facultad constitucionalmente garantizada y que se pone en riesgo al deber efectuarse diferenciaciones de planes y de otro orden.

La situación ha motivado una cuantiosa jurisprudencia de los tribunales superiores del país en torno al aumento unilateral de los planes de salud de las ISAPRES ${ }^{11}$, en que se ha fallado a favor de los recurrentes esgrimiendo argumentos que se pueden sintetizar del siguiente modo:

a) “... La revisión de los contratos de salud previsional por las ISAPRES no está concebida como una cláusula de reajustabilidad o de estabilización a favor de ellas, sino para salvar los mayores costos extraordinarios de las prestaciones basadas en aspectos imposibles de prever, que no habilitan modificaciones sin fundamento" 12 .

b) “... el proceder de la recurrida importa una violación a la garantía constitucional de la libre elección del sistema de salud, al derecho de propiedad y a la igualdad ante la ley, desde el momento que se está estableciendo una situación carente de fundamento, que impide a una persona mantenerse en el plan contratado alterando las condiciones previamente pactadas en el contrato, obligándola a emigrar a otro sistema, lo cual tiene obvia influencia lesiva en su patrimonio"13.

c) "La facultad revisora de la ISAPRE debe entenderse condicionada en su esencia a un cambio efectivo y plenamente comprobable del valor económico de las prestaciones médicas, en razón de una alteración sustancial de sus costos y no por un simple aumento debido a fenómenos inflacionarios o a la injustificable posición de que la variación pueda estar condicionada por la frecuencia en el uso del sistema, pues es de la esencia de este tipo de contrataciones la incertidumbre acerca de su utilización" 14 .

Si observamos esta jurisprudencia constitucional emanada de los tribunales ordinarios, es coincidente en tres aspectos: Primero, la variación de los contratos de salud no es admisible por los intereses de las ISAPRES, sino por circunstancias que acrediten un cambio efectivo en las condiciones de estos; segundo, justificar tal cambio en intereses de las administradoras o en procesos inflacionarios no se justifica; y tercero, la ausencia de una justificación real hace de la decisión arbitraria y una vulneración de la garantía de libre elección del sistema de salud, como asimismo del derecho de propiedad.

Como veremos, estas pretensiones de los afiliados en cuanto a evitar el aumento de precio de sus contratos de salud ha evolucionado hasta transformarse en una acción deducida en sede de inaplicabilidad por inconstitucionalidad ante el Tribunal Constitucional.

\footnotetext{
11 De los recursos de protección presentados contra ISAPRES el año 2008 fueron acogidos el 96,6\%, de acuerdo a estadísticas citadas en el Informe de Instituto Libertad y Desarrollo, Temas Públicos No 945,27 de noviembre de 2009.

12 Sentencia de la Corte de Apelaciones de Santiago de 22 de diciembre de 2008, Rol 10579/2008.

13 Sentencia de la Corte de Apelaciones de Santiago de 1 de octubre de 2008, Rol 6041/2008.

14 Sentencia de la Corte Suprema de 28 de diciembre de 2009, Rol 6909/2009.
} 


\section{ISAPRES Y LA INTERVENCIÓN DE LA JUSTICIA CONSTITUCIONAL EN UNA MATERIA TRADICIONALMENTE CONOCIDA POR LA JUSTICIA ORDINARIA}

El traspaso de la facultad de declarar inaplicable un precepto legal en razón de inconstitucionalidad, desde la Corte Suprema al Tribunal Constitucional tras la reforma constitucional de 2005, ha motivado que la temática de las prestaciones de salud y de sus costos ven los planes contratados con las ISAPRES se haya desplazado fuertemente a la Justicia Constitucional.

La jurisprudencia del juez constitucional, en los veintiún fallos relativos a ISAPRES dictados a la fecha ${ }^{15}$, dice relación fundamentalmente con el costo para los usuarios respecto de sus planes de salud y, más específicamente, a las situaciones en que estos precios varían, pudiéndose destacar los siguientes:

1. Respecto del artículo transitorio de la Ley 20.317, que da el carácter de irrenunciables a los excedentes de cotizaciones de salud, se han presentado dos requerimientos de inaplicabilidad por inconstitucionalidad. El fallo rol 1420 - $09^{16}$ declara inadmisible el requerimiento, porque la cuestión planteada no era de competencia del Tribunal Constitucional, y el segundo, rol $1442-09^{17}$, rechaza el requerimiento por ser este una reformulación del anterior.

2. A la fecha existen tres fallos que declaran inadmisibles requerimientos de inaplicabilidad del número 2 del artículo $2^{\circ}$ de la Ley $20.015^{18}$, norma que refiere a los

15 Estudio efectuado hasta el mes de abril de 2010, con la valiosa colaboración de mi ayudante alumna de la Facultad de Derecho de la Pontificia Universidad Católica señorita Ana Luisa Boldt Strickler.

16 Sentencia del Tribunal Constitucional de 9 de julio de 2009, Rol 1420-09.

${ }_{17}$ Sentencia del Tribunal Constitucional de 5 de agosto de 2009, Rol 1442-09.

18 "Artículo $2^{\circ}$.- Esta ley entrará en vigencia en la misma fecha en que entre a regir el primer decreto que contenga las Garantías Explícitas en Salud del Régimen General de Garantías en Salud.

Los contratos de salud previsional que se celebren con posterioridad a la entrada en vigencia de la presente ley deberán ajustarse a ella. Los contratos celebrados con anterioridad, se ajustarán a sus disposiciones en sus respectivas anualidades. Sin perjuicio de lo anterior, las siguientes materias se regirán por estas reglas:

1.- Los contratos de salud previsional cuyo precio, a la fecha de vigencia de la presente ley, se encuentren expresados en un porcentaje equivalente a la cotización legal y no sean de aquéllos a que se refiere el inciso final del artículo 39 de la ley No 18.933, ni aquellos celebrados por dos o más trabajadores en que se hayan convenido beneficios distintos a los que podrían obtener con su cotización individual, se mantendrán vigentes y solo podrán ser convertidos a unidades de fomento o a la moneda de curso legal vigente en el país si las partes así lo acuerdan expresamente o cuando se produzca un cambio de plan de salud por cualquier causa.

2.- Dentro del plazo fijado en el inciso primero de este artículo, la Intendencia de Fondos y Seguros Previsionales de Salud deberá establecer, mediante instrucciones de general aplicación, el diseño de la tabla de factores a que deberán sujetarse las Instituciones de Salud Previsional y las normas que sean necesarias para el debido cumplimiento de esta obligación.

A contar de la fecha en que entre en vigencia esta ley, las Instituciones de Salud Previsional deberán utilizar las nuevas tablas de factores en todos los nuevos contratos de salud que celebren. Todos los planes de salud que ofrezcan como alternativa las Instituciones en las adecuaciones que tengan lugar a partir de la fecha indicada deberán utilizar las nuevas tablas de factores.

Tratándose de contratos en curso a la fecha de entrada en vigencia de esta ley, las tablas de factores que ellos contengan se mantendrán en vigor hasta que el afiliado opte por aceptar un plan alternativo que se le ofrezca en alguna adecuación o hasta que contrate un plan de salud distinto. En todo caso, el proceso de adecuación de precios base que se efectúe entre la fecha en que entre en vigencia esta ley y el 30 de junio de 2006, inclusive, se desarrollará conforme a las disposiciones en vigor antes de la entrada en vigencia de esta ley y se regirá exclusivamente por ellas". 
efectos en el tiempo de la ley que regula la tabla de factores a que deben sujetarse las Instituciones de Salud Provisional. Es especialmente relevante respecto de los contratos celebrados con anterioridad a la entrada en vigencia de esta ley.

En los tres fallos (roles 1590 - 09, 1606 - 09 y 1581 - 09 ${ }^{19}$ ), el razonamiento es idéntico: se pide la impugnación del numeral segundo del artículo segundo, numeral que se encuentra a su vez dentro del inciso segundo del referido artículo. El texto a continuación del numeral segundo no forma parte de este, sino que corresponde a los incisos tercero y cuarto de este artículo, que igualmente regulan la aplicación de la nueva tabla de valores a los contratos de salud, especialmente los que se encontraban vigentes con anterioridad a esta ley. En todos los casos, estos incisos no forman parte del requerimiento de inaplicabilidad, por lo que, a juicio del tribunal, "no es la parte de la norma legal impugnada en este requerimiento la que, por sí sola y de manera aislada e independiente de otras disposiciones del ordenamiento jurídico, regula el sistema de revisión del precio del referido contrato de salud vigente (...) Y, por ende, al haberse cuestionado solo aquella regla legal, la impugnación que se formula en el requerimiento resulta insuficiente para entender cumplida la exigencia en comento, a los efectos de que esta Magistratura emita un pronunciamiento de inaplicabilidad por inconstitucionalidad" 20 .

El artículo 199 del DFL 1 del MINSAL 2005, que corresponde al artículo 38 ter de la Ley 18.933, determina las normas para fijar el precio del contrato de salud, según los precios base del artículo anterior, y la respectiva tabla de factores.

3. Por su parte, los fallos roles 1210 - 08, 1265 - 08 y 1376 - $09^{21}$ declararon inadmisibles los requerimientos, en los dos primeros casos por no ser la impugnación razonablemente fundada, y en el tercero, porque la requirente no acompañó los antecedentes solicitados por el tribunal. En el caso del fallo $1282-08^{22}$ es rechazado porque intenta dejar sin efecto una sentencia interlocutoria que declaró inadmisible la misma acción de inaplicabilidad por inconstitucionalidad, y los fallos 1222 - 08 y 1278 - $08^{23}$, por falta de gestión pendiente.

4. Existen tres fallos que acogen estos requerimientos: roles $976-07,1218-08$ y $1287-08^{24}$.

Si bien se trata, por supuesto, de tres casos distintos, lo que se pide, los derechos invocados, y el razonamiento del Tribunal Constitucional en estos tres fallos, son muy similares. Los requirentes al llegar a una determinada edad ingresan dentro del grupo de “cotizantes cautivos", reciben una "carta de adecuación” de la ISAPRE, que les notifica

${ }^{19}$ Sentencias del Tribunal Constitucional de 10 de marzo de 2010, Rol 1590-09; 14 de abril de 2010, Rol 1606-09 y 9 de marzo de 2010, Rol 1581-09.

${ }^{20}$ Sentencia del Tribunal Constitucional de 10 de marzo de 2010, Rol 1590-09.

${ }^{21}$ Sentencias del Tribunal Constitucional de 11 de septiembre de 2008, Rol 1210-08; 4 de noviembre de 2008, Rol 1265-08 y 19 de mayo de 2009, Rol 1376-09.

22 Sentencia del Tribunal Constitucional de 18 de diciembre de 2008, Rol 1282-08.

23 Sentencias del Tribunal Constitucional de 7 de julio de 2009 Rol 1222-08 y de 16 de diciembre de 2008, Rol 1278-08.

${ }^{24}$ Sentencias del Tribunal Constitucional de 26 de junio de 2008, Rol 976-07; 7 de julio de 2009, Rol 1218-08 y 8 de septiembre de 2009, Rol 1287-08. 
que debido a la tabla de factores y a su edad, causa que es determinante, se verificará un aumento sustancial en el valor del plan de salud, que califican de injusto y arbitrario.

Señalan que producto de esto deberán emigrar al sistema público de salud, lo que vulnera su libertad de elegir un sistema de salud; que se les discrimina en forma arbitraria en razón de su edad; y que su derecho a la propiedad se ve afectado, tanto por el aumento unilateral del costo del plan de salud, como porque al emigrar de sistema la ISAPRE se habría enriquecido injustamente, en tanto que sus propios patrimonios habrían disminuido considerablemente. Lo que se alega en esencia respecto del precepto aludido es:

a) La parte de dicho precepto que permite a las ISAPRES fijar un nuevo precio del plan de salud, aplicando al precio base el factor de rigor, multiplicado según lo autorizado por la Superintendencia en la tabla correspondiente. Este listado o nómina considera rubros tales como el sexo y la edad, distinción esta última que estiman constitucionalmente insostenible; y

b) La parte del precepto que autoriza a las Instituciones de Salud Previsional a determinar libremente los factores de la tabla homónima, sin otra limitación que la contenida en el inciso tercero de tal norma legal. Consiguientemente, al cumplir 75 años de edad, la aplicación de la regla descrita ha permitido un alza del factor que es de tal magnitud, que afecta a los requirentes en el costo de su plan de salud. Lo expuesto, atendida la disminución lógica de sus ingresos, secuela del envejecimiento natural de la persona, los ha dejado en la imposibilidad de pagar y, con ello, de mantenerse en el sistema de salud por el cual habían optado.

El Tribunal aborda estas cuestiones, como veremos, desde el derecho a la seguridad social, el derecho a la protección de la salud, derecho a la propiedad, y la supremacía constitucional sobre convenciones de particulares.

5. Sobre el precepto legal aludido se ha fallado una única acción de inconstitucionalidad, de rol $1444-09^{25}$, rechazada por no satisfacer la exigencia de contener una petición razonablemente fundada, en los términos del artículo $47 \mathrm{P}$ de la Ley Orgánica del Tribunal Constitucional, que exige indicar "precisamente la sentencia de inaplicabilidad previa en que se sustenta y los argumentos constitucionales que le sirven de apoyo". Señala el Tribunal que, sin perjuicio de que en el libelo se hayan invocado dos sentencias de inaplicabilidad previas sobre la misma materia, no se desarrollan los argumentos constitucionales que sustentan la pretensión. Los requirentes manifestaron que la inconstitucionalidad que solicitan "se funda en las mismas consideraciones" contenidas en los fallos citados. En el libelo se exponen además argumentos contradictorios con el control abstracto que se pide ejercer al tribunal, pues denuncian alzas específicas de planes de salud basadas en normas legales que no han sido objeto de reclamación.

En su considerando sexto, agrega que "la exigencia contenida en la Carta Fundamental de que se impugne 'un precepto legal' exige identificar, con precisión, de cuál de ellos se trata, no solo porque debe referirse a la misma norma que fue objeto de la

\footnotetext{
${ }^{25}$ Sentencia del Tribunal Constitucional de 31 de diciembre de 2009, Rol 1444-09.
} 
declaración previa de inaplicabilidad, sino porque, además, debe tenerse presente que el efecto propio de la declaración de inconstitucionalidad, de conformidad con el inciso tercero del artículo 94 de la Constitución, es la derogación del precepto reprochado y no de elementos técnicos o de instrumentos a que él aluda, como sería el caso de la tabla de factores' mencionada por los requirentes".

Esta sentencia fue acordada con el voto en contra de los Ministros señores José Luis Cea Egaña, Mario Fernández Baeza y Carlos Carmona Santander, quienes estuvieron por acoger a tramitación la acción de inconstitucionalidad deducida, por considerar que satisface los requisitos dispuestos en el artículo 47 P de la Ley No 20.381.

\section{LA ATRIBUCIÓN DEL TRIBUNAL CONSTITUCIONAL DE DECLARAR LA INAPLICABILIDAD POR INCONSTITUCIONALIDAD DE PRECEPTOS LEGALES Y SUS EFECTOS SOBRE EL SISTEMA JURÍDICO CHILENO}

La reforma de la Constitución efectuada en 2005, como se ha dicho, otorgó esta atribución al Tribunal Constitucional de haberla tenido antes la Corte Suprema y sin duda ello ha representado un considerable potenciamiento de su capacidad de control normativo. No cabe duda que la importancia de la jurisprudencia constitucional en esta materia no radica solo en determinar la inaplicabilidad de la norma en un caso concreto $^{26}$, sino que se traduce en una interpretación constitucional que abarca y pesa sobre el sistema normativo en su conjunto y sobre la jurisprudencia de los restantes órganos jurisdiccionales dadas las siguientes características:

1. La labor del Tribunal al conocer de la inaplicabilidad de un precepto legal, si bien se centra precisamente en el caso concreto y no representa un precedente obligatorio para la justicia ordinaria, evidentemente importa una interpretación constitucional con creciente fuerza vinculante, tanto porque el Tribunal sienta una línea de resolución de casos que se van repitiendo como verdaderas acciones de clase $^{27}$, como por el hecho que el juez ordinario es presionado para considerar como la correcta determinación del sentido y alcance de una norma es la proporcionada por el juez constitucional, es decir, el experto. El hecho mismo que la inaplicabilidad declarada por el Tribunal tenga por fin incidir en la resolución de un caso pendiente frente a otra instancia jurisdiccional innegablemente permea en esta aunque no comparta la postura del sentenciador constitucional y ello sin considerar la relevancia que para el propio juez ordinario tiene la posibilidad que le brinda la Constitución de plantear el mismo el requerimiento de declaración

\footnotetext{
${ }^{26}$ Lo cual importa determinar tres cotejos normativos en la decisión del juez constitucional: "la norma constitucional, el precepto legal cuya inaplicación se solicita y -lo más específicamente decisivo- el examen particular acerca de si, en ese caso, la aplicación del precepto cuestionado pudiera generar efectos contrapuestos a la finalidad implícita de aquélla": Ríos ÁlvAREZ (2005) p. 77.

27 Si bien el Tribunal en su sentencia de 6 de septiembre de 2007, Rol 616-06, ha expresado que: "en un caso determinado se declare un precepto legal inaplicable por inconstitucional, no significa que siempre y en cualquier caso procederá formular igual declaración", la realidad, cuando menos en el tema que nos ocupa, su interpretación ha sido totalmente unívoca en relación con la existencia misma de la tabla de factores por grupo etario.
} 
de inaplicabilidad. Adicionalmente, ha de tenerse presente que el momento en el cual se plantea la inaplicabilidad es coincidente con un caso determinado cuyo transcurso data de un cierto tiempo y el cual se han tomado decisiones previas o se han establecido resoluciones bajo una interpretación legal y constitucional que puede perfectamente diferir de aquella que efectúe el Tribunal Constitucional, "luego, la sentencia de la cuestión de constitucionalidad genera, en el fondo, efectos retroactivos, para las relaciones jurídicas ventiladas en una "gestión", litigio o conflicto, que no estuvieran agotadas por una decisión judicial pasada en autoridad de cosa juzgada" 28 .

2. La declaración de inaplicabilidad, aunque en apariencia refiera a una aplicación del precepto en un caso concreto, sin duda tiene un amplio efecto sobre la actividad, servicio, estatuto, orgánica o situación en la que el caso se encuentra inmerso. En efecto, la mayor parte de las veces la confrontación de la norma de rango legal con una de rango constitucional, refiere a la eventual vulneración de derechos que podría producir la primera y, para determinar tal cosa, no solo ha de dilucidarse el sentido y alcance del precepto acusado de trasgredir la Constitución, no que el sentenciador constitucional ha de avocarse en desentrañar la esencia de la garantía aludida dentro de la Constitución, como consecuencia de lo cual es ilusorio que fallo alguno en esta materia refiera solo al caso concreto.

3. La omnipresente posibilidad que, a consecuencia de la declaración de inaplicabilidad, de oficio o a petición de parte el Tribunal pueda declarar luego la inconstitucionalidad de la norma, lo cual implica su derogación por la vía jurisdiccional, sin duda representa una consecuencia que entraña cierto peligro: La intención inicial es revisar la aplicabilidad del precepto para un caso, pero resulta inevitable la estandarización de casos cuando en realidad lo que está detrás de las pretensiones de los interesados que acuden a esta instancia es la derogación de la norma o incluso el término de un determinado estatuto ${ }^{29}$, como puede serlo el modelo de seguros de salud aplicados al sistema privado de ISAPRES. De esta manera, la declaración de inaplicabilidad de la ley sin duda "debilita, sino anula, la presunción de constitucionalidad de la ley y cuestiona severamente el principio de seguridad jurídica. Más aún, mientras dure el contencioso constitucional, después de la admisión a trámite de la inaplicabilidad, se produce la sospecha de una eventual inconstitucionalidad, que también incide en la seguridad jurídica y en la estabilidad de las relaciones jurídicas" 30 .

4. En forma adicional a lo anterior, la actividad de interpretación misma de la Constitución que efectúa en esta materia el sentenciador puede no solo consistir en la determinación de la esencia de una garantía para confrontarla con la ley y hacerla así preferir a esta por la vía de la no vulneración consagrada en el artículo 19 No 26 de la

\footnotetext{
28 ZÚNIGGA URBina (2005) p. 42.

29 "El tema es de suyo polémico y de gran relevancia política ya que puede significar sacar del sistema jurídico un texto legal que ha sido aprobado por el Congreso Nacional y por el Presidente de la República como poderes colegisladores, desconociendo de esta manera la soberanía nacional contemplada en el artículo $5^{\circ}$ de la C.P. y que por representación la tiene el Congreso pero que corresponde en última instancia al Pueblo": SAENGER (2007).

30 ZÚNiga URBINA (2005) p. 43.
} 
Carta $^{31}$, sino que se puede transformar en un modo de efectuar una suerte de integración constitucional que dote de nuevos contenidos a una garantía o que determine su aplicación a materias no solo no previstas en el ordenamiento, sino que resultan del todo incompatibles con el estatuto leal aplicable que no tuvo a la vista ese modo de mirar o de crear derechos constitucionales, como ha sucedido en la especie con la jurisprudencia en comento en este trabajo: "las normas que regulan el contrato de salud, sean legales o administrativas, deben ser interpretadas y aplicadas en términos de maximizar el disfrute real y pleno de los derechos que son consustanciales a la dignidad humana, entre ellos el derecho social relativo a la protección de la salud, en los términos asegurados a todas las personas en el artículo 19, No $9^{\circ}$, de la Constitución, precepto que se erige en base constitucional y de orden público que informa, con calidad de ineludible e inafectable, toda convención de esa índole" (considerando cuadragésimo)/ "el derecho a la protección de la salud, en los términos en que se encuentra plasmado en el artículo 19, No 9o, de la Carta Fundamental, es la base constitucional y de orden público de todo contrato de salud, con plena vigencia en el contexto de dicha convención, razón por la cual esta no puede incluir cláusulas que desconozcan o aminoren tales derechos. Consiguientemente, estipulaciones de esa índole devendrían en inválidas por ser contrarias a la Constitución, efecto que tendría que contemplar estipulaciones que, directamente o no, signifiquen que la contraparte quede, de facto, impedida de ejercer la plenitud de todos y cada uno de los atributos que le han sido asegurados en esa disposición suprema" 32 .

31 "En efecto, el Tribunal Constitucional debe interpretar tanto el texto o disposición constitucional que sirve de parámetro, como el precepto infraconstitucional sometida a juicio. A su vez, los textos son multisemánticos, de ellos se extrae la norma como significado aplicado del texto. Por lo que de un mismo texto o disposición pueden obtenerse diversas normas entre las cuales debe decidir, lo que permite el desarrollo de las sentencias de interpretación conforme a la Constitución. Por otra parte, la Constitución dota al juez de la misión de ser guardián de la supremacía y fuerza normativa efectiva de la Carta Fundamental, dotándolo para ello del instrumento más eficaz para ello, la declaración de inconstitucionalidad, sin embargo no está obligado a utilizar dicha arma en todos los casos, ya que debe hacer un esfuerzo de conservación de las normas legislativas producto del parlamento y otorgar el máximo de certeza del derecho que integra el ordenamiento jurídico, además de evitar los vacíos normativos y evaluar las consecuencias de sus fallos, ello abre las puertas a la búsqueda de sentencias que constituyen respuestas realistas y flexibles frente a situaciones inconstitucionales que otorguen seguridad jurídica en la perspectiva de aplicación uniforme del derecho, lo que da nacimiento a las sentencias atípicas de los tribunales constitucionales": Nogueira AlCALÁ (2004).

32 Sentencia del Tribunal Constitucional de 7 de julio de 2009, Rol 1218-08. Sin duda, tal interpretación sobre el derecho a la protección de la salud como una garantía que es exigible sin límite a los particulares, aún intermediando en sus contratos, es una extensión efectuada por el Tribunal que excede el marco original del modelo de salud y de previsión social previsto por la Constitución. A mayor abundamiento, la estimación de la dignidad humana y de salud como medidas para el establecimiento de prestaciones resulta una limitación al dominio que, más allá del fundamento en la salubridad pública que busca el Tribunal, impone un deber de solidaridad no compatible con el estatuto jurídico y las legítimas expectativas de las instituciones de salud previsional para desarrollar su actividad, salvo que tal deber sea soportado con subsidio estatal adecuado. 


\section{EL TRATAMIENTO CONSTITUCIONAL DE LA TABLA DE FACTORES CONTEMPLADA EN EL ARTÍCULO 38 TER DE LA LEY No 18.933 -INTRODUCIDO POR LA LEY No 20.015-, QUE ACTUALMENTE CORRESPONDE AL ARTÍCULO 199 DEL DFL (MINISTERIO DE SALUD) $N^{\circ}$ 1, DE 2005: FUNDAMENTOS Y CONTROVERSIA}

La jurisprudencia del Tribunal Constitucional que ha acogido la solicitud de inaplicabilidad del artículo 199 del DFL No 1 MINSAL ha importado no considerar como factor de reajustabilidad de los costos de los planes de salud de beneficiarios de ISAPRES al factor etario. Con ello y por disposición del juez constitucional, se altera un sistema de salud privado definido en torno al concepto de seguros, autofinanciado además, forzando a que el aumento de riesgo de producirse siniestros asociados con la salud por el hecho de envejecimiento de las personas, no pueda invocarse para aplicar criterios conocidos por los contratantes y aplicar, según lo previamente convenido, un alza de las primas respectivas.

\section{TABLA DE FACTORES Y CONTRATO DE SALUD}

La tabla de factores establecida en el artículo 199 del DFL No 1 MINSAL de 2005 se corresponde con uno de los criterios legalmente establecidos y que admiten la reajustabilidad de los planes de salud. Tal normativa no es antojadiza, sino que corresponde a un modelo de salud privada establecido a principios de los años ochenta mediante la creación de las Instituciones de Salud Previsional (ISAPRES), entidades de giro único, sujetas a una regulación legal especial y sometidas a la fiscalización de la Superintendencia de Salud.

El modelo de salud privada establecido en la ley y vigente por casi treinta años, si bien coexiste con el sistema público depositado en FONASA, dualidad respecto de la cual la Constitución garantiza libre elección, no es sin embargo asimilable a él por varias causas:

a) El sistema FONASA implica el subsidio estatal a los beneficiarios, mientras el público afiliado a las ISAPRES no solo no recibe subsidio, sino que ha debido a través del tiempo ir incrementando su aporte al sistema, con una cotización que se compone en algo más de un $70 \%$ con la cotización legal y con un casi $30 \%$ de aporte adicional. Ello ha representado una disminución paulatina de los afiliados al sistema privado y la fuerte carga de los cotizantes activos.

b) Mientras al sistema FONASA el ingreso resulta automático y por disposición de la ley en un plan prácticamente único, el sistema de las ISAPRES importa la suscripción de contratos en los cuales existe la posibilidad de elección de determinados planes, de los cuales es parte integrante la determinación de coberturas asociadas con los costos y la posibilidad que se incrementen estos costos en la medida que los riesgos de entregar mayores coberturas aumenten.

c) En el caso de FONASA el monto de la prima se identifica exclusivamente con la cotización obligatoria sobre una remuneración imponible de hasta 60 unidades de fomento (UF) y los diferenciales que puedan llegar a existir son subsidiados por el 
Estado $^{33}$. En el sistema de ISAPRES, las primas son exclusivamente pagadas por los cotizantes y si estas se elevan por las causas previstas en la ley, estos deben asumir tal costo o migrar a un plan más barato. De esta manera, la dificultad que el sistema puede presentar para que las personas opten en realidad por el sistema de salud al que desean acogerse, no consiste en que uno sea más barato que el otro, sino en realidad en que uno está subsidiado y el otro no, por lo cual los costos reales para el beneficiario decrecen en el primero y necesariamente aumentan en el segundo.

2. LAS Claves de los fallos del Tribunal CONSTitucional en esta MATERIA (FALLOS ROLES 976 - 07, 1218 - 08 y 1287 - 0834)

Los argumentos esgrimidos por el juez constitucional en relación con la inaplicabilidad de la norma comentada han sido sintéticamente los siguientes:

a) Deber de los particulares respecto de la protección de la salud: "aplicando dicho criterio de hermenéutica constitucional y siendo la Carta Fundamental un sistema orgánico y coherente de valores, principios y normas, todos los cuales guardan entre sí correspondencia y armonía, excluyendo cualquiera interpretación que anule o prive de eficacia a algún precepto de ella, cabe insistir en que no solo los órganos del Estado deben respetar y promover los derechos consustanciales a la dignidad de la persona humana, sino que esa obligación recae también en los particulares, aunque sea subsidiariamente, puesto que el Código Supremo asegura la intangibilidad de tales atributos en toda circunstancia, cualesquiera sean los sujetos que se hallen en la necesidad de infundir vigencia efectiva a lo proclamado en sus preceptos" 35 . Es importante la precisión acerca de un deber subsidiario, puesto que en los fallos luego no aparece como tal este deber.

b) Obligación de las instituciones de salud previsional de no afectar los derechos en su esencia o menoscabar su libre ejercicio: “... habiéndoles reconocido el Poder Constituyente a las Instituciones de Salud Previsional, como manifestación del principio de subsidiariedad, la facultad de intervenir en el proceso de satisfacer el derecho constitucional a la protección de la salud de sus afiliados, en los términos contemplados en el precepto respectivo, ellas deben, siempre y en todo caso, procurar que los derechos consustanciales a la dignidad de la persona humana, en especial aquel cuya satisfacción les ha sido reconocida y está amparada por la Carta Fundamental, no sean afectados en su esencia o menoscabados por la imposición de condiciones o requisitos que impidan su libre ejercicio, con sujeción a lo previsto en el artículo 19, No 26º de la Carta Política" ${ }^{36}$. Tal aseveración forzará, como ya se ha comentado en este trabajo, a definir la esencia del derecho a objeto de hacer el examen que la solicitud de inaplicabilidad exige.

33 El cual, así, garantiza un sistema prestacional solidario.

34 Sentencias del Tribunal Constitucional de 26 de junio de 2008, Rol 976-07; 7 de julio de 2009, Rol 1218-08 y 8 de septiembre de 2009, Rol 1287-08.

35 Sentencia del Tribunal Constitucional de 26 de junio de 2008, Rol 976-07.

36 Ídem. 
c) En razón de lo anterior y de acuerdo al considerando cuadragésimo del fallo de 7 de julio de 2009, Rol 1218-0837, idéntico a su vez al considerando trigésimo noveno del fallo de 26 de junio de 2008, Rol 976-07, el Tribunal considera que la interpretación de las normas legales que regulan el contrato de salud entre privados deben ser interpretadas en clave del disfrute máximo de los derechos respectivos ${ }^{38}$. Esta aseveración del Tribunal sin duda excede considerablemente el marco de la inaplicabilidad para el caso concreto, pues importa la reconsideración de los contratos de salud propiamente tales pero podría significar la revisión de otras fórmulas, como es el caso de los contratos de seguros complementarios. De esta manera, la intervención de la justicia constitucional en contratos privados intermediados por el concepto de servicio público, el cual en todo caso cautela la ley, genera obligaciones importantes para los particulares no previstas por nuestro ordenamiento, como se ha reconocido incluso por la literatura que elogia los fallos en estudio: "el derecho humano a la protección de la salud o -desde la perspectiva del Derecho Internacional de los derechos humanos- el derecho de toda persona al disfrute del más alto nivel posible de salud física y mental, impone límites y obligaciones tanto a los órganos públicos como a los particulares, en razón del valor y principio constitucional de la solidaridad./ Este valor y principio de la solidaridad, por la vía de los derechos sociales, determina, limita y condiciona las actuaciones de los particulares, entre sí y en sus convenciones privadas. Dicho de otro modo, la solidaridad, como valor y principio de orden objetivo con base constitucional, traducido -en este caso- en los derechos sociales, limita y subordina, incluso, la autonomía privada. En consecuencia, a través del Derecho, particularmente desde la óptica de los derechos fundamentales, se pueden resolver problemas sociales, indicando y orientando, al mismo tiempo, el diseño y ejecución de las políticas públicas, especialmente, de las políticas sociales implementadas por el Estado"39.

d) El contrato de salud se halla intermediado por la interpretación de los derechos fundamentales, sin perjuicio de su regulación legal: “... si bien la Isapre, al establecer los factores de la tabla incorporada al contrato de salud de la requirente, puede haberse atenido a las normas legales y administrativas que rigen tal operación, no debe olvidarse que, en las estipulaciones de ese contrato de salud, tienen que ser

\footnotetext{
37 Ya citado.

38 "En nuestra opinión, los antecedentes de hecho y de derecho de la sentencia del TC permiten concluir que en el contexto de los cargos y rasgos propios del derecho a la protección de la salud el Estado de Chile ha avanzado de manera expedita y eficaz en las últimas décadas en las condiciones básicas de salud de la población y ha controlado con la debida diligencia, mediante la ley y los órganos que la ejecutan, los comportamientos de los actores no estatales. Los antecedentes de la causa en que incide la sentencia que se comenta son prueba de lo afirmado. Aplicar idénticos criterios de exigibilidad al Estado y los particulares en el respeto y promoción del derecho a la protección de la salud es desconocer el rol y las características de uno y otro, y puede conducir a la falta de certeza jurídica y fáctica, cuyas consecuencias serían imprevisibles. Por otra parte, las consideraciones del fallo de mayoría sobre la magnitud del alza de los precios de los planes de salud introducen, en nuestra opinión, un elemento de duda si se relaciona con lo resolutivo del mismo": BATES (2009).

39 Aguilar Cavallo (2008).
} 
respetados y promovidos los atributos que integran el derecho a la protección de ella, asegurado a la señora ... en el artículo 19, № 9º de la Carta Fundamental. Ciertamente, este efecto de la supremacía no puede quedar condicionado, diferido o supeditado a lo que preceptúen tales normas porque se hallan subordinadas a lo mandado en la Constitución" (considerando quincuagésimo quinto)/ "el efecto de irradiación del texto, contexto y espíritu de la Constitución en el contrato celebrado entre la requirente y requerida en el caso concreto y singular sub lite significa que tanto las normas legales como las administrativas o las estipulaciones contractuales tienen que ser interpretadas y llevadas a la práctica en armonía con el reconocimiento y tutela del derecho a la protección de la salud, asegurado en aquélla" (considerando quincuagésimo sexto)/ "consiguientemente, no cabe sino concluir que toda facultad que por ley se otorgue a las ISAPRES de fijar libre o discrecionalmente un factor para incorporarlo a dichas contrataciones, debe suponerse siempre limitada por los valores, principios y disposiciones constitucionales, deducción lógica que, si fuera desconocida o ignorada, sería equivalente a quebrantar el valor de la supremacía que singulariza a la Constitución” ${ }^{40}$. Como es obvio, esta adecuación de los contratos a una interpretación constitucional a posteriori no consulta preguntarse por los derechos de los demás usuarios del sistema a los que aún no se aplica la tabla de factores ni tampoco examina las posibilidades de subsistencia del sistema mismo. e) El derecho a la elección del sistema de salud importa mantenerse en el elegido más allá de los compromisos contractualmente adquiridos: "siendo base constitucional y de orden público del contrato de salud previsional la prevista en el artículo 19, No $9^{\circ}$, de la Carta Política, cuyo inciso final reconoce el derecho de la requirente a elegir el sistema de salud al que desea acogerse y acorde con la idea de sistema coherente de valores, principios y preceptos ya expuesta, deviene irrebatible que todas las cláusulas del referido contrato deben orientarse a materializar el goce real y legítimo de dicho derecho, más todavía si el afiliado envejece y, a raíz de ello, sube considerablemente el factor respectivo, lo cual repercute en el mayor costo de su plan de salud. Con ello, lejos de permitir el acceso a las prestaciones correlativas, las dificulta y, en el caso extremo, cuando el afiliado no puede seguir pagando el nuevo costo del plan, cual sucede en la causa aquí decidida, queda obligado a abandonar el sistema privado de salud que había escogido para incorporarse al equivalente público. Obviamente, el hecho descrito significa que el afectado se halla impedido de ejercer tales derechos, a pesar de estarle asegurados por la Constitución en cualquier tiempo y circunstancia" (considerando sexagésimo primero) ${ }^{41}$.

f) En voto disidente, los ministros Juan Colombo Campbell, Raúl Bertelsen Repetto y Jorge Correa Sutil expresan su parecer en orden a: "Mal puede, entonces, estimarse que el legislador ha actuado de modo irrazonable cuando permite a instituciones privadas proveedoras de seguros de salud alzar, dentro de ciertos márgenes y de conformidad a las instrucciones generales emitidas por la autoridad administra-

40 Sentencia del Tribunal Constitucional de 7 de julio de 2009, Rol 1218-08.

41 Ídem. 
tiva competente, los precios que cobra por un contrato destinado a cubrir los costos de salud, cuando cambian factores que, como está probado, son determinantes para aumentar el riesgo que se asegura"/ "... la Constitución no asegura a las personas poder permanecer en un determinado plan o seguro de salud, ni menos a hacerlo por un precio inalterable. La obligación impuesta al Estado $-\mathrm{y}$ no a instituciones particulares- de proteger el libre e igualitario acceso a las acciones de promoción, protección y recuperación de la salud, que la Constitución sí establece, es diversa a los derechos de las personas a permanecer en un plan o más precisamente a mantener inalterable un precio de un seguro destinado a cubrir los costos en que incurran en materia de salud. Si bien existe una relación entre aquella obligación -impuesta solo al Estado- y que dice relación con las acciones de salud y el derecho que se pretende, que se refiere al modo de financiar el acceso a esas acciones de salud, la diferencia entre ambas resulta evidente, tanto desde el punto de vista del sujeto obligado como de la naturaleza de la obligación constitucional y el derecho que se pretende, ya que es distinta una prestación de salud que el seguro destinado a cubrir todo o parte del costo de la misma"/ "Los derechos a elegir que la Constitución asegura, en este y otros casos, no conllevan la garantía de que el precio del bien esté al alcance de todos. No puede sostenerse que la Carta Fundamental que nos rige consagre el acceso igualitario a un seguro de salud, independiente de la capacidad de pago de la persona. Tal independencia entre un bien y su acceso universal e igualitario se ha logrado respecto a ciertas prestaciones de salud, a través del Plan Auge, sistema de gratuidad que la Constitución permite, pero que no hace obligatorio y menos para los contratos con ISAPRES, que no son prestaciones de salud, sino sistemas para cubrir los riesgos económicos de ese bien"/ “...es inexacto afirmar que en Chile todo sistema de seguridad social haya de ser necesariamente solidario, siendo ella una opción no excluida, por cierto, en la Constitución Política, pero no prescrita por esta. Mal puede, entonces, deducirse de una base constitucional inexistente consecuencias jurídicas que llevarían, no solo a estimar inconstitucional la aplicación judicial de un determinado precepto legal -en el caso que nos ocupa el artículo 38 ter de la Ley No 18.933-, sino, a estimar contrario a la Carta Fundamental todo el sistema privado de seguros de salud previsional ${ }^{42}$.

\footnotetext{
42 Ídem. La última frase transcrita es, a nuestro juicio, la clave del tema, pues el artículo declara inaplicable por el fallo de mayoría no ves escindible del modelo al cual pertenece. Si consideramos que la garantía del artículo 19 No 90 importa o significa que la libre elección del sistema de salud debe ser una realidad material para todas las personas, las brechas o umbrales del ejercicio del derecho deben ser ante todo asumidas por el colectivo bajo la forma de subsidios o incentivos, ya que de otro modo la superación de las barreras de entrada al sistema pasa a ser una obligación de los particulares que son los mismos que ya están asumiendo como población activa el deber de autofinanciamiento de este. En la norma en comento, la ISAPRE está obligada a proponer planes alternativos a los afiliados que no pueden sostener sus planes por aumento de estos, pero adicionar a dicha ecuación una obligación de subsidio privado para mantener el plan del cotizante representa, a nuestro juicio, transformar las garantías prestacionales en fórmulas que gravan los contratos legalmente suscritos y que no representan limitaciones del dominio en razón de su función social, sino la imposición de desmedros patrimoniales respecto de los afiliados que soportan el sistema y que necesariamente deberían pagar para asegurar las prestaciones que otros reciben, todo lo cual amenaza la subsistencia del modelo.
} 
3. LAS CONSECUENCIAS DE LOS VOTOS DE MAYORÍA DE LOS FALLOS EN ESTUDIO: EL PROBLEMA DE LAS GARANTÍAS PRESTACIONALES: RECURSOS VERSUS IGUALDAD

Si bien coincidimos con el sentenciador en que los derechos económicos y sociales no han de ser tratados peyorativamente en relación con los derechos civiles y políticos, y que en ambos grupos puede existir la necesidad de consagrar garantías de orden prestacional, ello no es lo mismo que establecer como una condición de todo contrato el brindar prestaciones a todo evento o el mantener inalterable un estatus determinado adquirido bajo ciertas condiciones objetivas que con posterioridad varían.

El principio de igualdad constitucional, así, alude a establecer un estatuto común a quienes se encuentran en similares circunstancias, pero no importa forzar ese estatuto beneficioso para quienes han variado estas, como podría ser mantener el estatuto de funcionario público a quien ha concluido su mandato, mantener los beneficios de paciente a quien ya no lo es o asegurarle a una persona obtener prestaciones con costo económico aunque no cubre dichos $\operatorname{costos}^{43}$. En aquellos casos de limitación de recursos, la igual protección de la ley en el ejercicio de los derechos es una garantía que impide efectuar discriminaciones arbitrarias y que demanda por parte del Estado suplir las falencias de estos a favor de los particulares, como sucede en el caso del derecho a defensa jurídica, pero no podría transformarse en un arma que exija de los prestadores particulares efectuar servicios gratuitos $^{44}$, o más aún, alterar las bases que fundan un sistema como lo es el de la

${ }^{43}$ Contra ello se pronunció el propio Tribunal Constitucional: "la garantía jurídica de la igualdad supone, entonces, la diferenciación razonable entre quienes no se encuentren en la misma condición; pues no se impide que la legislación contemple en forma distinta situaciones diferentes, siempre que la discriminación no sea arbitraria ni responda a un propósito de hostilidad contra determinada persona o grupo de personas, o importe indebido favor o privilegio personal o de grupo, debiendo quedar suficientemente claro que el legislador, en ejercicio de sus potestades, puede establecer regímenes especiales, diferenciados y desiguales, siempre que ello no revista el carácter de arbitrario" (Rol No 986/2008). En palabras del Tribunal Constitucional español, "no toda desigualdad de trato resulta contraria al principio de igualdad, sino aquella que se funda en una diferencia de supuestos de hecho injustificados de acuerdo con criterios o juicios de valor generalmente aceptados" (STC 128/1987).

44 “... así como se consagra el derecho a la asistencia jurídica, le corresponde al Estado -a través del legislador- establecer medios efectivos que permitan una adecuada defensa de aquellas personas que carezcan de bienes suficientes para litigar. En tal sentido, la Ley No 19.718, de 10 de marzo de 2001, estableció en materia criminal la Defensoría Penal Pública, de modo tal que esta defensa se efectúa a través de una institución estatal, por sí misma o vía licitación a privados, a quienes, obviamente, se remunera por sus servicios profesionales en conformidad a las bases respectivas. Por su lado, décadas antes, en el ámbito civil -bajo la estructura de la Corporación de Asistencia Judicial- la legislación estableció una práctica profesional, en virtud de la cual se obliga a todo egresado de Derecho a atender gratuitamente a aquellas personas que sean beneficiarias del denominado privilegio de pobreza... Que la imposición de la obligación de defender a determinadas personas de escasos recursos constituye un fin razonable, pero el medio utilizado por el legislador -la gratuidad- sin duda se transforma en gravoso, máxime si se piensa que el abogado deberá dedicarse sin contraprestación pecuniaria alguna a atender numerosos asuntos en desmedro de aquellos que ha asumido libremente, lo que se tornará en una situación imposible de acometer, y aun de ejecutar de manera satisfactoria e idónea, más todavía si se tiene presente que la obligación se mantendrá hasta el término efectivo del juicio, lo que importará un largo período de tramitación. Como se aprecia, para cumplir con el mandato constitucional de dar asistencia legal a quienes no están en condiciones de procurársela por sí mismos, el legislador puede emplear el medio - por cierto excepcional y supletorio- de 
salud privada en Chile con marcado perjuicio de la población activa que financia el sistema y que también goza de garantías prestacionales en torno a él.

Como, a nuestro juicio correctamente, lo ha manifestado el voto disidente transcrito, en la materia las declaraciones de inaplicabilidad del artículo 199 del DFL 1 MINSAL (2005) se han transformado, mucho más allá de la objeción de aplicación de la norma a un caso concreto, en un reparo general al sistema de salud privado en Chile y en un cuestionamiento al modo de establecer la variación de las primas asociada dicha regla contractual al aumento del riesgo objetivo, como sucede en todos los modelos de seguros del mundo.

Sin duda, y de acuerdo a tratados internacionales vigentes en Chile, el principio de solidaridad con los grupos vulnerables, como es el caso de las personas ancianas o de la situación de quienes presentan discapacidad, importa para ellas la elevación favorable de sus posibilidades de acceso al sistema prestacional y a los servicios que les son necesarios precisamente en asociación a esa vulnerabilidad, pero los modelos correspondientes no se asientan ni se apoyan en imponer esta obligación a los particulares, sino en suplementar los recursos disponibles por parte del propio Estado, ya sea con prestaciones directas, subsidios o incentivos, los que por cierto no pueden transformarse en herramientas de desmedro para el resto de las personas.

El problema, lejos de lo que pueden imaginarse quienes visualizan este caso como una arena de conflicto entre ISAPRES y usuarios del sistema de salud privado, en realidad radica en las posibilidades de acceder a las garantías prestacionales por parte del colectivo no vulnerable, o no vulnerable en apariencia para ser precisos: es decir, el conjunto de personas que financian el sistema cada vez con mayores incrementos y que lo usan comparativamente mucho menos. Ese conjunto de personas afectadas no goza en estos fallos de una especial consideración ni a sus derechos ni a su patrimonio, ni tampoco se prevén por el sentenciador las formas de cautelar su migración inevitable al sistema de salud público po una elevación general de los costos de los planes de salud con independencia del factor etario.

En efecto, el juez constitucional, con el objeto benevolente de asegurar no la elección del sistema sino la permanencia en él por parte de grupos vulnerables, ha descuidado las posibilidades de permanencia de los demás usuarios, que con inferiores rangos de riesgo, pagarán altas primas hasta que esa posibilidad ya no les sea viable.

\section{LA EVENTUAL DEROGACIÓN DEL PRECEPTO QUE PUEDE DERIVARSE DE LAS DECLARACIONES DE INAPLICABILIDAD HASTA AHORA DICTADAS}

Como ya se ha explicado, las atribuciones del Tribunal Constitucional establecidas en la reforma de 2005 han importado el peligro de una declaración de inconstitucionalidad con efecto derogatorio como una posible consecuencia de los fallos de

obligar a los abogados a desempeñar esta tarea, pero ello no autoriza la circunstancia de que no se remunere dicha labor profesional. Así, tal carga de gratuidad no aparece ni se justifica como un medio necesario para alcanzar el fin constitucional perseguido": Sentencia del Tribunal Constitucional de 29 de julio de 2009, Rol 1254-08. 
inaplicabilidad. De hecho, en la materia, ya ha habido una solicitud de así declararlo que fue declarada inadmisible por aspectos formales, lo que no evita que se reintente. Sin perjuicio de ello, el Tribunal ha abierto la causa Rol No1710-10. INC, Proceso de inconstitucionalidad iniciado de oficio por el Tribunal con relación al artículo 38 ter de la Ley No 18.933, el cual al cierre de este artículo se encuentra en tramitación y con oficios dirigidos tanto al Ejecutivo como al Congreso Nacional para conocer su postura.

A nuestro juicio, la derogación del precepto impugnado constituiría una decisión muy grave tanto desde la perspectiva formal como sustantiva.

En efecto:

a) Sistema de salud privado sin tabla de factores: ¿Es una posibilidad viable?

El establecimiento de criterios de reajustabilidad de los contratos de seguros, asociando la cobertura de estos al riesgo soportado, sin duda es una característica propia de estos, la cual explica la razón misma de la actividad de seguros y las razones por las cuales es desarrollada por los particulares en goce de su derecho a la libre empresa garantizado en el artículo $19 \mathrm{~N}^{\circ} 21^{\circ}$ de la Constitución Política. Precisamente por tratarse, en el caso de las prestaciones de salud, de una actividad regulada por un servicio asociado con derechos fundamentales, esos criterios a la libre determinación de las partes y no a la decisión del legislador, a fin de que sean objetivos, ponderados y objetivables.

De acuerdo a la supremacía constitucional establecida en el artículo $6^{\circ}$ de la Carta y al hecho que los derechos fundamentales son un límite a la soberanía del Estado, las reglas legales destinadas a la actividad prestadora en salud de los particulares no pueden desconocer los derechos que la propia Constitución protege, pero tampoco el juez constitucional ha de ignorar que la actividad aseguradora en sí está sometida a ciertas reglas básicas que no se pueden alterar salvo que se quiera considerar que la actividad misma se opone a la Constitución, lo cual claramente no ha sido declarado en ningún país occidental.

De lo anterior se colige que los criterios de reajustabilidad admitidos por el legislador no solo se orientan a la mantención de las instituciones prestadoras, sino que soportan la estructura misma del sistema y su eliminación no agrega a este el rasgo de solidario pretendido, sino que lo transforma en un modelo altamente inequitativo para muchos de sus usuarios y susceptible de colapso por la imposibilidad de mantenerlo sin hacer desagregaciones asociadas con el riesgo de suceso del siniestro y con las prestaciones ofrecidas.

La introducción de un criterio de solidaridad en el funcionamiento del sistema no se puede hacer con cargo sencillamente a los particulares, porque transforma por la cara inversa, en un gravamen para unos la protección de la extensión de derechos que formula para otros, ya que los unos han de sostener la onerosidad creciente de un modelo en el cual los otros no aumentan su colaboración sobre la existencia de un derecho a mantener las condiciones prestacionales existentes, derecho que solo podría derivar del aporte prestacional del Estado en representación del colectivo interesado en subsidiar las prestaciones de salud para los pacientes vulnerables. 
En consecuencia, la tabla de factores solo puede ser eliminada en la medida que el Estado provea los diferenciales para mantener el aporte necesario de acuerdo los riesgos que importa la condición del grupo beneficiado. Por desgracia, al provenir tal eventual decisión de un órgano jurisdiccional no existirá compromiso ni política asociada a tal decisión que se agregue como complemento a la decisión del juez constitucional y, como consecuencia, este cargará a solas con las consecuencias de sus fallos al no tener el sistema obligación de suplir los vacíos que se originan.

La dictación de fallos exhortativos o declaraciones que insten a los legisladores y al Ejecutivo a pronunciarse no resolverá el problema.

\section{b) Finalmente: ¿Quién resuelve el problema de la falta de norma?}

Si las sentencias examinadas se tradujeran en un fallo de inconstitucionalidad, el Tribunal Constitucional no tiene la facultad de dictar una norma de reemplazo ni el poder de forzar o demandar tal dictación. Si bien se han intentado tramitar proyectos que establecen una moratoria en la decisión derogatoria de normas por parte de esta instancia ${ }^{45}$ y el propio Tribunal ha buscado transmitir en sus decisiones la importancia de legislar en coordinación con ellas, tal cosa no representa ningún criterio de seguridad y, más aún, traspasa la solución del problema constitucional generado a un ente de especialidad diversa y funcionamiento pausado.

A nuestro juicio, la jurisprudencia comentada devela, por parte del voto de mayoría del Tribunal, una voluntad proclive a la protección de los colectivos vulnerables en materia de salud que sin duda se ajusta al espíritu de los DES, pero a nuestro entender tal voluntad se desvía en su buen propósito al crear una suerte de derecho a la mantención en el sistema de salud que la Constitución no ha previsto y que no se puede sostener del modo pretendido por el juez constitucional, como asimismo al reprochar de inconstitucional una normativa que es propia del sistema de seguros y cuyos efectos han de ser paliados ya sea por autorregulación de las aseguradoras en torno a la existencia de alternativas aceptables a los planes de salud encarecidos o el aporte solidario del Estado. Estimar que las eventuales inequidades del modelo de salud privado han de resolverse con carga a los demás usuarios o traspasando al legislador la carga de crear en tiempo breve un sistema equitativo no solo no resultará una solución constitucionalmente deseable, sino que redundará en la destrucción del sistema privado de salud sin un plan de acción alternativo.

\footnotetext{
45 El Proyecto de Reforma del artículo 94 de la Constitución Política de la República, referido a la constitucionalidad de un precepto legal, Boletín $\mathrm{N}^{\circ}$ 6221-07, actualmente en tramitación, dispone en su Artículo único: "Agregar en el artículo 94 de la Constitución Política de la República el siguiente inciso $5^{\circ}$ nuevo, del siguiente tenor: Sin perjuicio de lo expresado en los incisos anteriores, el Tribunal con la misma mayoría de los cuatro quintos de sus integrantes en ejercicio, tendrá la facultad de diferir en el tiempo el efecto de la decisión a que se refiere el $n^{\circ} 7$ del artículo 93, hasta por un plazo máximo de un año”.
} 


\section{BIBLIOGRAFÍA}

Aguilar Cavallo, Gonzalo (2008): "Principio de solidaridad y derecho privado: comentario a una sentencia del Tribunal Constitucional”, Ius et Praxis - año $14-\mathrm{n}^{\circ} 2$, 2008, pp. 593-610.

Aguilera Portales, Rafael y Espino Tapia, Diana Rocío (2006): "Fundamento, garantías y naturaleza jurídica de los Derechos sociales ante la crisis del estado social de Derecho", Revista Telemática de Filosofía del Derecho, no 10, 2006/2007, pp. 111 139.

ALEXY, Robert (2001): Teoría de los derechos fundamentales (traducción castellano Ernesto Garzón Valdés) (Madrid, Centro de Estudios Políticos y Constitucionales, 2a edición).

BATES, Luis (2009): "Sentencia del Tribunal Constitucional que declara inaplicable norma de la ley de ISAPRES y derechos económicos, sociales y culturales", Anuario de Derechos Humanos de la Universidad de Chile, 2009, disponible en: http:// www.cdh.uchile.cl/publicaciones/anuarios (fecha de consulta: abril de 2010).

Gomes CANOTILHO, Jose Joaquim (1995): "Metodología "Fuzzy" y "camaleones normativos" en la problemática actual de los derechos económicos, sociales y culturales", Derechos y Libertades, disponible en http://e-archivo.uc3m.es/dspace/bitstream/10016/ 1319/1/DyL-1995-III-6-Gomes-Cantonilho-.pdf (fecha de consulta: abril de 2010).

Moller, Max (2008): "La aplicabilidad de los derechos Sociales prestacionales en los sistemas jurídicos contemporáneos”, Tesis doctoral Universidad de Burgos, Facultad de Derecho. Disponible en http://dspace.ubu.es:8080/tesis/bitstream/10259/88/1/ M\%c3\%b6ller.pdf (fecha de consulta: abril de 2010).

Nogueira AlCAlA, Humberto (2004): "Consideraciones Sobre las Sentencias de los Tribunales Constitucionales y sus Efectos en América del Sur”, Ius et Praxis Año 10 $\mathrm{N}^{\circ}$ 1: 113-158.

PRIETO SANCHIS, Luis (1995): "Los derechos sociales y el principio de igualdad sustancial", Revista del Centro de Estudios Constitucionales No 22 (septiembre-diciembre 1995) pp. 9-57.

Ríos Álvarez, Lautaro (2005): "Trascendencia de la reforma constitucional en la fisonomía y las atribuciones del Tribunal Constitucional”, Revista del Centro de Estudios Constitucionales, Año 3, No 1 (2005) pp. 73-95.

Rosselot, Enrique (2003): “Aspectos bioéticos en la Reforma de la Atención de Salud en Chile. II. Discriminación, libre elección y consentimiento informado", Rev. méd. Chile v.131 n.11 Santiago nov. 2003, pp. 1329-1336. Disponible en: http:// www.scielo.cl/s cielo.php? script =s ci_art text \& pid = S 0034 98872003001100016\&lng=es\&nrm=iso (fecha de consulta: abril de 2010).

SAENGER, Fernando (2007): "Acción de Inaplicabilidad e Inconstitucionalidad. Facultades del nuevo Tribunal constitucional. Algunos casos jurisprudenciales", Estudios Constitucionales, Año $5 \mathrm{~N}^{\circ}$ 1, pp. 305-348. Disponible en http://www.cecoch.cl/ $\mathrm{htm} / \mathrm{revista} / \mathrm{docs} /$ estudiosconst/revistaano_5_1_htm/accion_de\%20Inap_5_12007.pdf (fecha de consulta: abril de 2010). 
STEIN, Kuhnle (1991): "Estado de bienestar", en BODANOR, Vernon (editor), Enciclopedia de las Instituciones Políticas (Madrid, Alianza Editorial).

ZúNIIGA URBINA, Francisco (2005): "La sentencia de "inaplicabilidad”- cuestión de constitucionalidad y legislación”, Estudios constitucionales, año/vol 3 No 001, pp. 37-53.

\section{JURISPRUDENCIA CITADA}

Corte de Apelaciones de Santiago: Recurso de protección Rol 641/2008, 1 de Octubre 2008.

Corte de Apelaciones de Santiago: Recurso de protección Rol 10579/2008, 22 de Diciembre de 2008.

Corte Suprema: Recurso de Protección Rol 6909/2009, 28 de Diciembre de 2009.

Tribunal Constitucional: Recurso de Inaplicabilidad, Rol 616-06, 6 de septiembre de 2007.

Tribunal Constitucional: Recurso de Inaplicabilidad, Rol 986-08, 1 de Diciembre de 2008.

Tribunal Constitucional: Recurso de Inaplicabilidad, Rol 976-07, 26 de Junio de 2008.

Tribunal Constitucional: Recurso de Inaplicabilidad Rol 1210-08, 11 de Septiembre de 2008.

Tribunal Constitucional: Recurso de Inaplicabilidad, Rol 1265-08, 4 de Noviembre de 2008.

Tribunal Constitucional: Recurso de Inaplicabilidad, Rol 1278-08, 16 de Diciembre de 2008.

Tribunal Constitucional: Recurso de Inaplicabilidad, Rol 1282-08, 18 de Diciembre de 2008.

Tribunal Constitucional: Recurso de Inaplicabilidad, Rol 1376-09, 19 de Mayo de 2009.

Tribunal Constitucional: Recurso de Inaplicabilidad, Rol 1254-08, 29 de Julio de 2009,

Tribunal Constitucional: Recurso de Inaplicabilidad, Rol 1218-08, 7 de Julio de 2009.

Tribunal Constitucional: Recurso de Inaplicabilidad, Rol 1222-08, 7 de Julio de 2009.

Tribunal Constitucional: Recurso de Inaplicabilidad, Rol 1420-09, 9 de Julio de 2009.

Tribunal Constitucional: Recurso de Inaplicabilidad, Rol 1442-09, 5 de Agosto de 2009.

Tribunal Constitucional: Recurso de Inaplicabilidad, Rol 1287-08, 8 de Septiembre de 2009.

Tribunal Constitucional: Recurso de Inaplicabilidad, Rol 1581-09, 9 de Marzo de 2010.

Tribunal Constitucional: Recurso de Inaplicabilidad, Rol 1590-09, 10 de Marzo de 2010.

Tribunal Constitucional: Recurso de Inaplicabilidad, Rol 1606-09, 14 de Abril de 2010.

Tribunal Constitucional: Recurso de Inconstitucionalidad, Rol 1444-09, 31 de Diciembre de 2009.

Tribunal Constitucional Español: Sentencia 128/1987, 16 de julio de 1987. 